\title{
Co-localization and interaction of human organic anion transporter 4 with caveolin-1 in primary cultured human placental trophoblasts
}

\author{
Woon Kyu Lee ${ }^{1,2}$, Jung Kyoung Choi ${ }^{3}$ \\ and Seok Ho Cha ${ }^{4,5}$ \\ ${ }^{1}$ The DNA Laboratory of Hankook Life Science Institute co. Ltd. \\ Seoul 405-207, Korea \\ ${ }^{2} \mathrm{MAP}$ Co. Ltd. \\ Wonju 220-842, Korea \\ ${ }^{3}$ Department of Physiology and Biophysics \\ ${ }^{4}$ Department of Pharmacology and Toxicology \\ and Center for Advanced Medical Education by BK21 Project \\ Inha University \\ Incheon 402-751, Korea \\ ${ }^{5}$ Corresponding author: Tel, 82-32-890-0957; \\ E-mail, shcha@inha.ac.kr \\ DOI 10.3858/emm.2008.40.5.505
}

Accepted 16 May 2007

Abbreviations: hOAT4, human organic anion transporter 4; ODN, oligodeoxynucleotide

\begin{abstract}
The human organic anion transporter 4 (hOAT4) has been identified as the fourth isoform of OAT family. hOAT4 contributes to move several negatively charged organic compounds between cells and their extracellular milieu. The functional characteristics and regulatory mechanisms of hOAT4 remain to be elucidated. It is well known that caveolin plays a role in modulating proteins having some biological functions. To address this issue, we investigated the co-localization and interaction between hOAT4 and caveolin-1. hOAT4 and caveolin-1 (mRNA and protein expression) were observed in cultured human placental trophoblasts isolated from placenta. The confocal microscopy of immuno-cytochemistry using primary cultured human trophoblasts showed hOAT4 and caveolin-1 were co-localized at the plasma membrane of the cell. This finding was confirmed by Western blot analysis using isolated caveolae-enriched membrane fractions and immune-precipitates from the trophoblasts. When synthesized cRNA of hOAT4 along with scrambled- or antisense-oligodeoxynucleotide (ODN) of Xenopus caveolin-1 were
\end{abstract}

co-injected to Xenopus oocytes, the $\left[{ }^{3} \mathrm{H}\right]$ estrone sulfate uptake was significantly decreased by the co-injection of antisense ODN but not by scrambled ODN. These findings suggest that hOAT4 and caveolin-1 share a cellular expression in the plasma membrane and caveolin-1 up-regulates the organic anionic compound uptake by hOAT4 under the normal physiological condition.

Keywords: caveolin 1; estrone sulfate; organic anion transporter 4

\section{Introduction}

The organic anion transporter (OAT) contributes to excrete amphiphilic organic anions introduced endogenously and exogenously including a number of clinically used drugs, pesticides and herbicides (Pritchard and Miller, 1993; Ullrich and Rumrich, 1993; Meier, 1995; Muller and Jansen, 1997). In the body, lipid-soluble compounds are biotransformed to their hydrophilic metabolites that are, in most cases, organic anions and many of them are harmful to the body. Their elimination, therefore, is essential for the maintenance of homeostasis. In 1997, Sekine et al. and Sweet et al. (Sekine et al., 1997; Sweet et al., 1997) used a functional expression cloning method to identify the novel multispecific organic anion transporter 1 (OAT1) from rat kidney. Now five murine (OAT1, 2, 3, 5, and 6) and five human (OAT1, 2, 3, 4, and 5) isoforms have been reported (Kusuhara et al., 1999; Cha et al., 2000, 2001; Sekine et al., 2000; Sun et al., 2001; Youngblood and Sweet, 2004; Monte et al., 2004). Among human OATs, only OAT4 is expressed in and cloned from human placenta.

The placenta has important roles in protecting the fetus from harmful compounds in the maternal circulation, supplying nutrients to the fetus, eliminating wastes from the fetus, and secreting bioactive compounds such as hormones and prostaglandins (Stulc, 1997; Knipp et al., 1999). The placental trophoblast differentially expresses a variety of transporters on the brush-border and basal membranes (Stulc, 1997; Ganapathy et al., 2000). Recently the human OAT4 is added to placental transporters. Although the only a few investigations 
have reported the functional characterization of hOAT4, there is no report on the regulating mechanism by protein-protein interaction between hOAT4 and caveolin.

In recent decades, the caveolins have been reported as being important modulating molecules that bind to some proteins having biological functions. Caveolins are integral membrane proteins that are present in caveolae, the small flask-shaped and detergent in soluble invaginations in the plasma membrane, and they have been implicated to function in the vesicular transport processes. Several studies have shown that several transporter protein including $p$ glycoprotein (Cai et al., 2004), cationic amino acid transporter (McDonald et al., 1997) and sodiumcalcium exchanger (Cha et al., 2004) are localized in caveolin-enriched lipid raft microdomains and they are regulated by caveolins. We first report that rat OAT3 also binds to and regulates its function by caveolin-1 (Kwak et al., 2005). Not only hOAT4 but also the several types of organic anion transporting protein and $\mathrm{ABC}$ transporters are expressed in placenta (Pascolo et al., 2003; Ugel et al., 2003). These facts can establish the hypothesis that hOAT4 also have relationship with caveolin.

Therefore, the purpose of this study was to investigate the protein-protein interaction between hOAT4 and caveolin-1, and regulatory effect of caveolin-1 on the function of hOAT4.

\section{Materials and Methods}

\section{Drugs and chemicals}

PCR primers, AMV reverse transcriptase $X L$ and Taq DNA polymerase were purchased from TaKaRa Korea Biomedical Co. (Seoul, Korea). TRI reagent and protein A-sepharose were purchased from Sigma-Aldrich (St. Louis, MO). Streptomycin, penicillin, Hanks' balanced salt solution (HBSS), DMEM and FBS were bought from Gibco BRL (Grand Island, NY). [ $\left.{ }^{3} \mathrm{H}\right]$ estrone sulfate was purchased from PerkinElmer Life Science Products (Boston, MA). Polyclonal rabbit anti-human OAT4 was purchased from Alpha Diagnostic International Inc. (San Antonio, TX). Monoclonal mouse anti-human caveolin-1, goat anti-mouse and anti-rabbit lgG: HRP antibodies were purchased from Transduction Laboratories (Lexington, MS). All other chemicals utilized in this study were of the highest purity available from commercial sources.

\section{Isolation of human trophoblast cells}

The placental tissue was from caesarian delivery patient and approved by the Inha University Institutional Research Board. Ten to $15 \mathrm{~g}$ human term placenta from donor was aseptically isolated during caesarian delivery and placed in HBSS. The tissue was cut in small pieces and trophoblast cells were isolated as described previously in detail elsewhere (Bischof et al., 2003) with modifications. Briefly, tissues were digested by $0.25 \%$ trypsin (Sigma) and DNase I (Sigma) at $37^{\circ} \mathrm{C}$, then trophoblast cells were separated from blood cells and decidua on a discontinuous Percoll gradient (Sigma). The cells were plated at $1 \times 10^{7}$ cells/ dish in $10 \mathrm{~cm}$ dish, $5 \times 10^{6}$ cells/well in 6-well plates and $1 \times 10^{5}$ cells/well in 24-well with DMEM medium supplemented with $20 \%$ FBS and $1 \%$ penicillin/streptomycin and kept in $5 \% \mathrm{CO}_{2}$ at $37^{\circ} \mathrm{C}$. This method supplies a $85 \sim 90 \%$ purity of trophoblastic cells, including all trophoblastic sub-groups. We verified the purity of trophoblast cells by using immunoblot with specific antibodies to cytokeratin 7 (positive) commonly used for indication of trophoblast purity.

\section{RT-PCR analysis and CDNA construction of hOAT4}

Extraction of total RNA was conducted by using the TRI reagent according to the manufacturer's instructions. Isolated total RNA (500 ng) from 6 -well culture was reverse transcribed using $5 \mathrm{U}$ of AMV reverse transcriptase $\mathrm{XL}$ for $30 \mathrm{~min}$. The prepared cDNA was employed as template for PCR. The condition for PCR was as follows; one cycle of $60 \mathrm{~s}$ at $94^{\circ} \mathrm{C}, 35$ cycles each for $30 \mathrm{~s}$ at $94^{\circ} \mathrm{C}, 30 \mathrm{~s}$ at $55^{\circ} \mathrm{C}$ and $90 \mathrm{~s}$ at $72^{\circ} \mathrm{C}$, and one cycle of $10 \mathrm{~min}$ at $72^{\circ} \mathrm{C}$. The PCR products $(15 \mu \mathrm{l})$ were then separated in a $1 \%$ agarose gel electrophoresis and stained with ethidium bromide. In order to obtain full sequence of hOAT4, PCR method was employed. PCR amplification was carried out and sub-cloned at the EcoRI and Xhol site in mammalian expression vector, pcDNA 3.1(+) and the sequence was confirmed using Big-dye method. The sequences of used primer sets are shown in Table 1.

\section{Western blot analysis}

The cells were washed with cold HBSS and harvested. Subsequently the cells and scrambled or antisense ODN-injected 50 Xenopus laevis oocytes were homogenized in nine volumes of 2.1 $\mathrm{M}$ sucrose solution containing $0.26 \mathrm{unit} / \mathrm{ml}$ aprotinin, $0.1 \mathrm{mM}$ PMSF, $10 \mu \mathrm{g} / \mathrm{ml}$ leupeptin, and $10 \mu \mathrm{g} / \mathrm{ml}$ trypsin inhibitor with 10 strokes of a motor-driven Teflon-glass tissue homogenizer. The homogenate was centrifuged for $10 \mathrm{~min}$ at $500 \times \mathrm{g}$, and the supernatant was centrifuged further for $20 \mathrm{~min}$ at 
Table 1. Nucleotide sequences of used primers.

\begin{tabular}{|c|c|c|}
\hline & Sequence & size \\
\hline \multicolumn{3}{|l|}{ hOAT4 } \\
\hline $\mathrm{F}$ & $\begin{array}{l}\text { TGGACACACATGCTGGAC- } \\
\text { AATGGC }\end{array}$ & 497 \\
\hline $\mathrm{R}$ & $\begin{array}{l}\text { AGTGAACTCAGAAAGATG- } \\
\text { CCGGCC }\end{array}$ & \\
\hline \multicolumn{3}{|l|}{ Cytokeratin-7 } \\
\hline $\mathrm{F}$ & $\begin{array}{l}\text { TTGCCTCCTTCATCGA- } \\
\text { CAAGGTGC }\end{array}$ & 502 \\
\hline $\mathrm{R}$ & $\begin{array}{l}\text { TCATACTGTGCCTTGA- } \\
\text { CCTCAGCG }\end{array}$ & \\
\hline \multicolumn{3}{|l|}{ caveolin-1 } \\
\hline $\mathrm{F}$ & $\begin{array}{l}\text { TCTACAAGCCCAACAA- } \\
\text { CAAGGCC }\end{array}$ & 360 \\
\hline $\mathrm{R}$ & $\begin{array}{l}\text { TGCACTGAATCTCAAT- } \\
\text { CAGGAAGC }\end{array}$ & \\
\hline \multicolumn{3}{|l|}{ hOAT4 } \\
\hline $\mathrm{F}(\mathrm{EcoRI})$ & $\begin{array}{l}\text { GCGCGCGAATTCGTTC- } \\
\text { CAAACAGCAGTTAGG }\end{array}$ & 2,220 \\
\hline$F(X h o l)$ & $\begin{array}{l}\text { GCGCGCCTCGAGTTTT- } \\
\text { TATCTGGCAGCTCTC }\end{array}$ & \\
\hline $\begin{array}{l}\text { X. caveolin-1 } \\
\text { SODN } \\
\text { X. caveolin-1 }\end{array}$ & GCCGGTCATCAGAGAGCA & \\
\hline AODN-1 & TGCTCTCTGATGACCGGC & \\
\hline
\end{tabular}

F, forward; R, reverse; SODN, scrambled-oligodeoxynucleotide; AODN, antisense-oligodeoxynucleotide

$8,000 \times g$. The supernatants were then centrifuged at $100,000 \times g$ for $1 \mathrm{~h}$, and the pellets containing crude membrane fractions were used to Western blotting. The protein samples were boiled for $10 \mathrm{~min}$ in sample buffer and subjected to $10 \%$ SDS-PAGE. The separated proteins were transferred electrically to a Hybond-P PVDF transfer membrane (Amersham Pharmacia Biotech). The membrane was blocked for $1 \mathrm{~h}$ in $5 \%$ skimmilk-TBST (20 mM Tris/HCl [pH 7.0], $150 \mathrm{mM}$ $\mathrm{NaCl}$, and $0.1 \%$ Tween 20), washed with TBST, and then incubated with antibodies of hOAT4 $(1: 500)$ or caveolin-1 $(1: 200)$ for $1 \mathrm{~h}$ at room temperature. The membrane washed three times in TBST was incubated for $1 \mathrm{~h}$ with the goat anti-rabbit or anti-mouse IgG:HRP antibody $(1: 3,000)$ at room temperature. After washing, the membrane was visualized by the ECL kit (Amersham Pharmacia Biotech., Buckinghamshire, UK).

\section{Confocal microscopy}

The primary cultured proximal tubular cells on cover slips were fixed with $4 \%$ para-formaldehyde solution in PBS ( $\mathrm{pH} 8.4 ; 15$ min, room temperature) and permeabilized by $0.1 \%$ Triton $\mathrm{X}-100$ solution in PBS (10 $\mathrm{min}$, room temperature). The nonspecific binding sites were blocked with $10 \%$ control serum in PBS for $30 \mathrm{~min}$ in room temperature. Polyclonal antibody of hOAT4 $(1: 200)$ and monoclonal antibodies of caveolin-1 (1:50) were treated to the fixed cells for $1 \mathrm{~h}$. Secondary antibodies without prior antibody treatment were also included as controls. After washing, cells were double stained with fluorescein isothiocyanate (FITC)- and Texas Red-conjugated secondary antibodies for $30 \mathrm{~min}$. After washing, samples were examined both at the green and red wavelengths under a Bio-Rad MRC 1000 confocal microscope. More than 50 cells have been inspected per experiment and the photos of cells with typical morphology and staining are presented.

\section{Preparation of caveolae-enriched membrane fractionation}

Caveolae-rich membrane fraction from cultured trophoblast was fractionated using sucrose gradient ultracentrifugation (Kwak et al., 2006). In brief, 2 plates $(\Phi 10 \mathrm{~cm})$ of cultured trophoblasts were harvested and homogenized in $2 \mathrm{ml}$ of lysis buffer (10 mM Tris-HCL, pH 7.5, $150 \mathrm{mM} \mathrm{NaCl}, 5 \mathrm{mM}$ EDTA, $1 \mathrm{mM}$ PMSF, $10 \mu \mathrm{g} / \mathrm{ml}$ leupeptin, $10 \mu \mathrm{g} / \mathrm{ml}$ trypsin inhibitor, and $1 \%$ Triton $\mathrm{X}-100$ ) followed by sonication. The homogenate was brought to $40 \%$ sucrose by addition of an equal volume of $80 \%$ sucrose and loaded in an ultracentrifuge tube. A discontinuous sucrose gradient was layered on top of the sample by placing $4 \mathrm{ml}$ of $30 \%$ and $4 \mathrm{ml}$ of $5 \%$ sucrose, respectively. After centrifugation at $200,000 \times g$ for $16 \sim 20 \mathrm{~h}$ at $4^{\circ} \mathrm{C}$, the upper light scattering band at the $5 \sim 30 \%$ sucrose interface was collected as the caveolae-rich fraction and the lower band (40\% sucrose layer) was collected as the non-caveolae fraction.

\section{Immuno-precipitation of hOAT4 and caveolin-1}

The soluble lysate of trophoblast was incubated with antibodies specific for caveolin-1, hOAT4 or a pre-immune rabbit $\lg G$ at a final concentration of 4 $\mu \mathrm{g} / \mathrm{ml}$ for $4 \mathrm{~h}$ at $4^{\circ} \mathrm{C}$. Protein-A-Sepharose was then added for $2 \mathrm{~h}$ at $4^{\circ} \mathrm{C}$. Thereafter, the samples were centrifuged and the pellets were washed 4 times with PIPA buffer (150 mM NaCl, 1 mM EDTA, $1 \%$ triton $\mathrm{X}-100,1 \% \mathrm{NP}-40,0.05 \%$ SDS, and 10 $\mathrm{mM}$ Tris; $\mathrm{pH}$ 8.0) and then prepared for the Western blotting analysis by boiling in the sample buffer to determine whether interactive binding has occurred between caveolin-1 and hOAT4. 


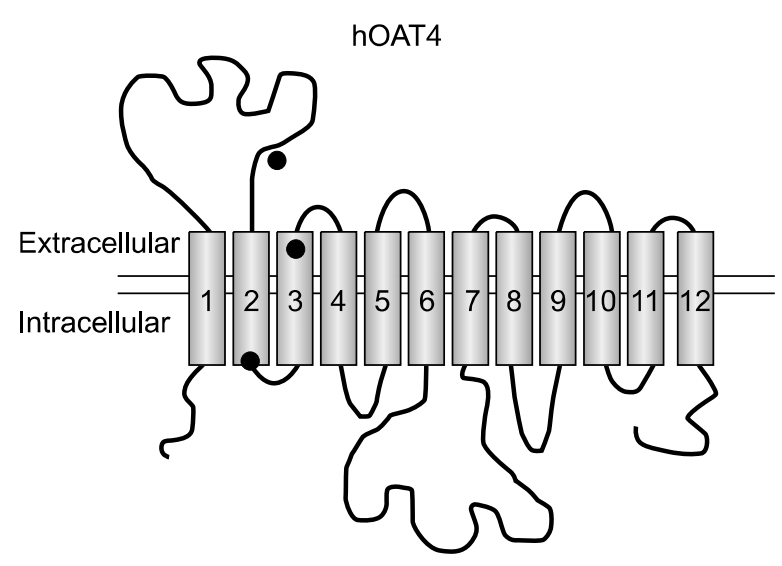

Figure 1. Predicted location of hOAT4 caveolin-binding motifs. The hydropathy plot model of hOAT4 is based upon topological analysis. Transmembrane regions are represented by shaded cylinders and extramembranal loops are black lines. Closed circles designate the approximate location of the hOAT4 caveolin-binding motifs.

\section{A}

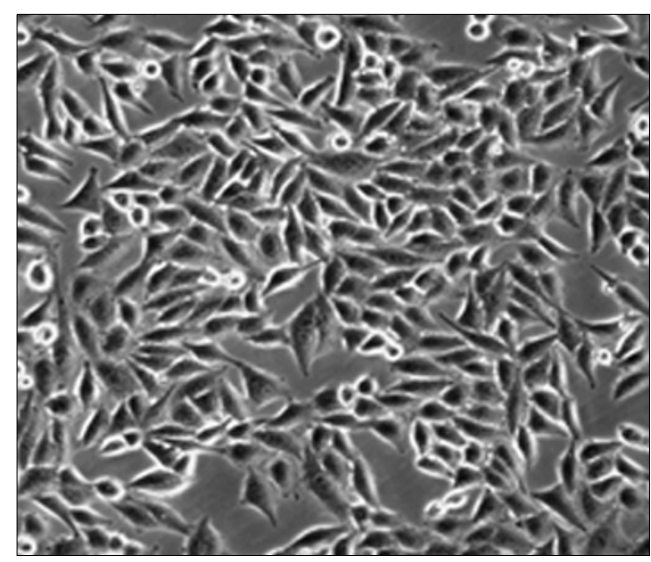

C

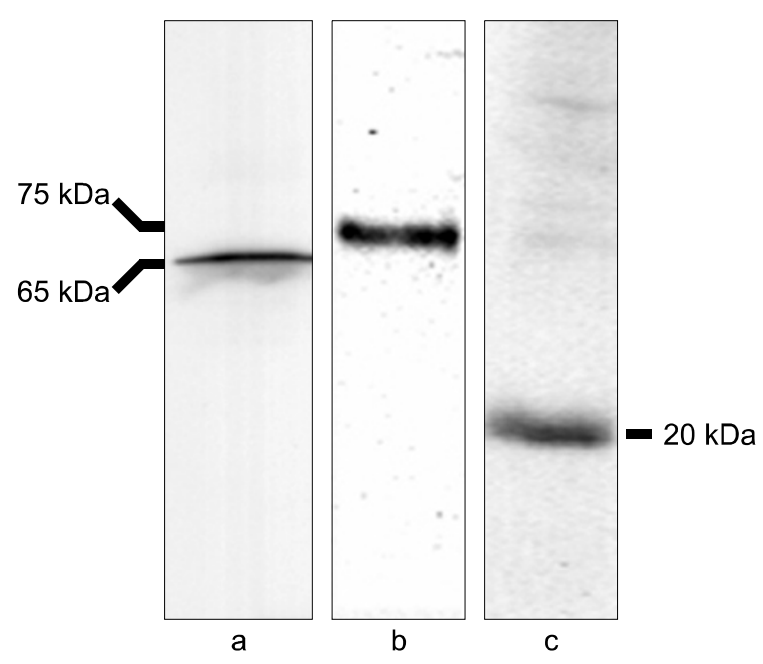

\section{cRNA synthesis and uptake experiments using Xenopus laevis oocytes}

cRNA synthesis and uptake measurements were performed as described previously (Cha et al., 2000). The capped cRNA was synthesized in vitro using T7 RNA polymerase from the plasmid DNA linearized with Xhol. Defolliculated oocytes (stage $\mathrm{VI}$ and $\mathrm{V}$ ) were injected with $30 \mathrm{ng}$ of the capped hOAT4 CRNA with or without Xenopus caveolin-1 sense or antisense oligodeoxynucleotides (ODN) and incubated in Barth's solution $(88 \mathrm{mM} \mathrm{NaCl}, 1$ $\mathrm{mM} \mathrm{KCl}, 0.33 \mathrm{mM} \mathrm{Ca}\left(\mathrm{NO}_{3}\right)_{2}, 0.4 \mathrm{mM} \mathrm{CaCl}, 0.8$ $\mathrm{mM} \mathrm{MgSO}_{4}, 2.4 \mathrm{mM} \mathrm{NaHCO}_{3}$, and $10 \mathrm{mM} \mathrm{HEPES}$ ) containing $50 \mu \mathrm{g} / \mathrm{ml}$ gentamicin at $18^{\circ} \mathrm{C}$. After 2 to 3 days of incubation, an $\left[{ }^{3} \mathrm{H}\right]$ estrone sulfate uptake experiment was performed at room temperature in ND96 solution $(96 \mathrm{mM} \mathrm{NaCl}, 2 \mathrm{mM} \mathrm{KCl}, 1.8 \mathrm{mM}$ $\mathrm{CaCl}_{2}, 1 \mathrm{mM} \mathrm{MgCl} 2$ and $5 \mathrm{mM} \mathrm{HEPES}, \mathrm{pH}$ 7.4) as described elsewhere (Kwak et al., 2005). Used

B

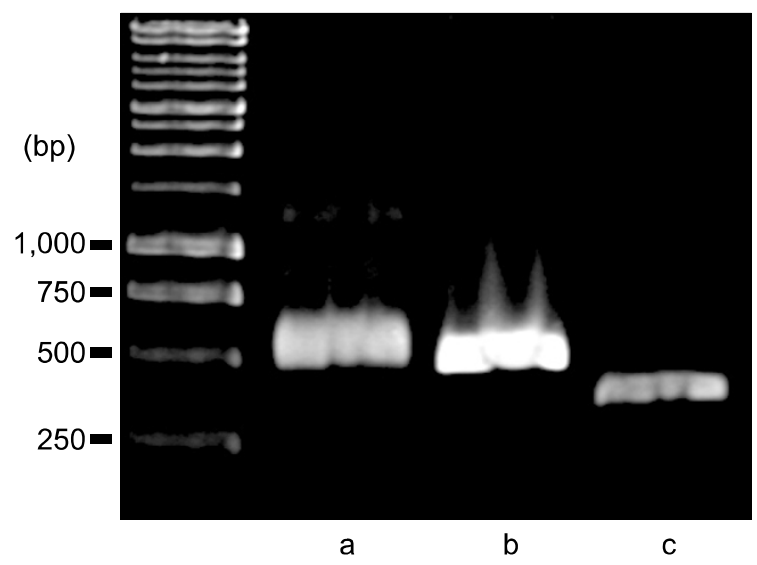

Figure 2. Morphology and characterization of primarily cultured placental trophoblasts. (A) Light microscopy of confluently grown placental trophoblasts. (B) Messenger RNA expression of cytokeratin-7, hOAT4 and caveolin-1 in the cultured placental trophoblasts. Total RNA (500 ng) isolated from cultured trophoblasts was reverse transcribed and PCR was performed (35 cycles). PCR products were separated using 1\% agarose gel and stained with ethidium bromide. (C) Isolated membrane protein $(30$ $\mu \mathrm{g} /$ lane) was separated by electrophoresis and presence of each cytokeratin-7, hOAT4 and caveolin-1 was detected with respective antibodies. Data was shown typical result from 3 independent experiments. a; cytokeratin-7, b; hOAT4, c; caveolin-1. 
antisense oligodeoxynucleotide sequences are also shown in Table 1.

\section{Statistical analysis}

Statistical analyses were performed using the ANOVA test for multiple comparisons and a $P$ value $<0.05$ was considered significantly different.

\section{Results}

\section{Caveolin-binding motifs in hOAT4}

As the first step of this study, we scanned the caveolin-binding motif in hOAT4. A scan of hOAT4 primary amino acid sequence indicated there are three potential caveolin-binding motifs located at amino acids 117-124, 158-167 and 193-201 (Figure $1)$. Two caveolin-binding motifs are located within the putative membrane spanning domains and near the extracellular face (117-124 and 193-201), and a motif is located near the cytoplasmic face of the plasma membrane (158-167).

\section{Human trophoblasts culture and identification}

We have characterized primarily cultured human placental trophoblasts using RT-PCR and immuno-
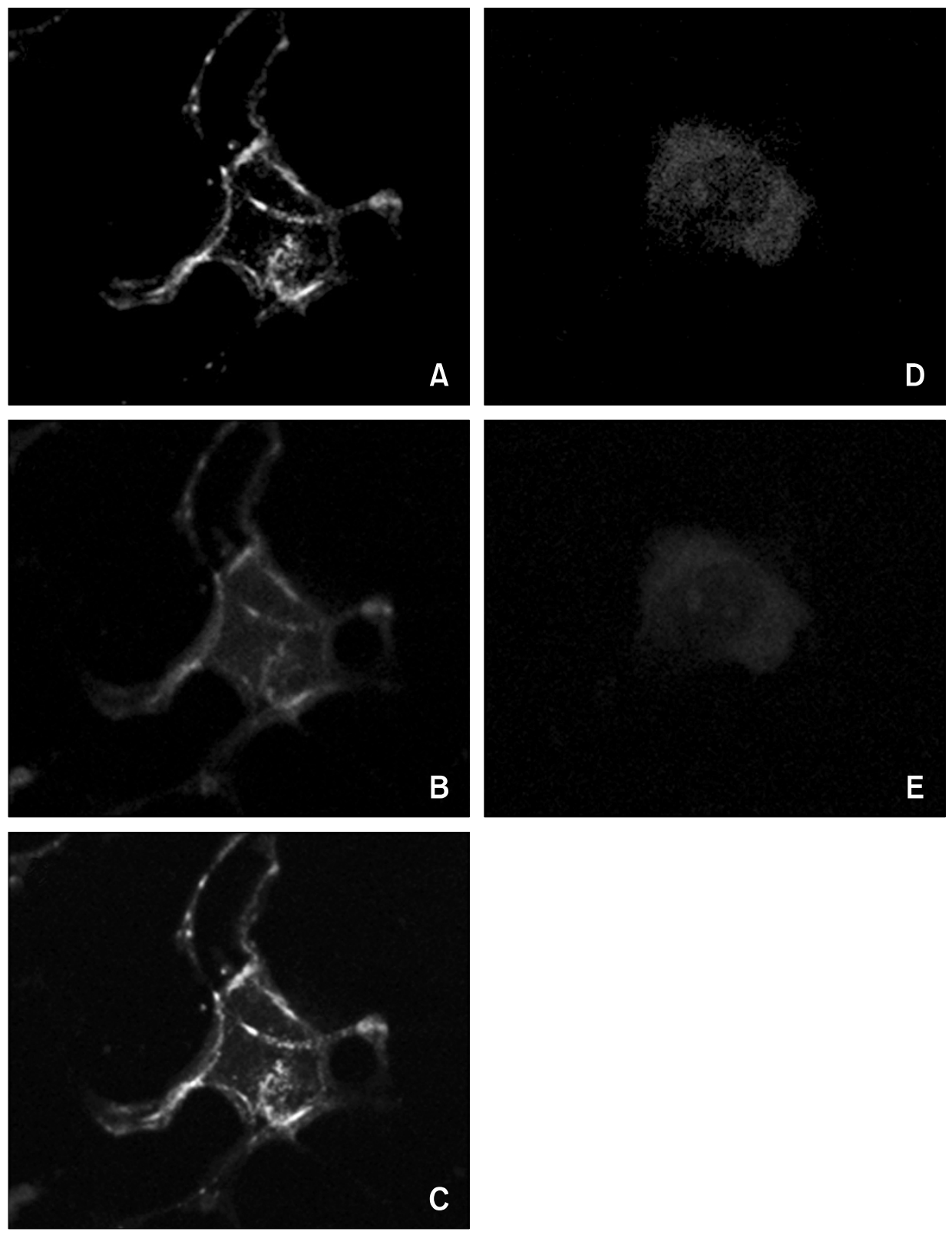

Figure 3. Confocal microscopy of cultured trophoblasts immuno-cytochemically stained with hOAT4 and caveolin-1 antibodies. Cells were double stained with fluorescein isothiocyanate- and Texas Red-conjugated secondary antibodies after an initial treatment with either hOAT4 or caveolin-1 antibodies separately and then examined under a confocal microscope at their respective wavelengths. For each experiment, at least 50 cells were examined and the presented images represent typical staining pattern for the majority of examined cells. A; hOAT4, B; caveolin-1, $C$; merged images of $A$ and $B$. $D$ and $E$, stained only with secondary antibodies without the prior treatment of either hOAT4 or caveolin-1 antibodies to show the images of non-specific bindings. 
blotting employing cytokeratin 7 (positive control) as the markers. Figure $2 \mathrm{~A}$ showed light microscopic morphology of primarily cultured human placental trophoblasts. Figure $1 \mathrm{~B}$ and $\mathrm{C}$ showed the mRNAs and protein expression of the trophoblast marker, hOAT4 and caveolin-1. From these results, used cells in current study had the characteristics of trophoblasts.

\section{Co-localization of hOAT4 and caveolin-1 in plasma membrane}

To demonstrate the localization of hOAT4 and caveolin-1 in the plasma membrane, we used confocal microscopy on the trophoblast cells. The cells were treated with the antibodies to hOAT4 or caveolin-1. Subsequently these cells were treated by double staining with two different secondary antibodies, one was conjugated with fluorescein isothiocyanate (hOAT4) and the other was conjugated with Texas Red (caveolin-1), respectively. The green fluorescent hOAT4 stain was localized to the plasma membrane (Figure $3 \mathrm{~A}$ ) and the red fluorescent caveolin-1 stain ws also detected in the plasma membrane as well as cytoplasmic portion (Figure 3B). The overlaid image showed the colocalization of hOAT4 with caveolin-1 (Figure 3C). Non-specific staining by the secondary antibodies

\section{B}

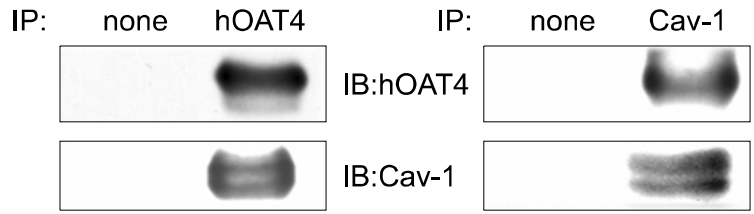

Figure 4. Western blot analysis using isolated membrane fraction and immunoprecipitates by antibodies in the cultured trophoblasts. (A) The cells were lysed using a teflon/glass homogenizer and a sonicator, and subjected to sucrose gradient centrifugation as described under Materials and Methods. Equal amounts of protein $(10 \mu \mathrm{g})$ from each of twelve fractions $(1-12)$ were separated by SDS-PAGE $15 \%$ acrylamide gel and transferred to membranes, which were blotted using anti-hOAT4 antibody (1:500) and anti-caveolin-1 (1:200). Obtained data from 2 separate experiments were consistent. (B) Cell lysates were immuno-precipitated initially with antibodies of hOAT4 or caveolin-1 and the respective immuno-precipitated (IP) proteins (15 $\mu \mathrm{g})$ were loaded onto each lane of a 10\% SDS-polyacrylamide gel. Cell lysate was immuno-precipitated initially with hOAT4 (left pannel) and was immuno-precipitated initially with caveolin-1 antibodies (right pannel). Obtained data from 2 separate experiments were consistent.

A

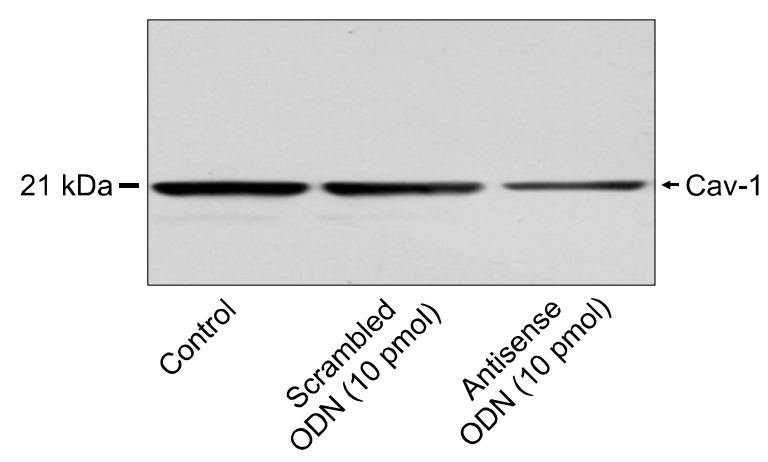

B

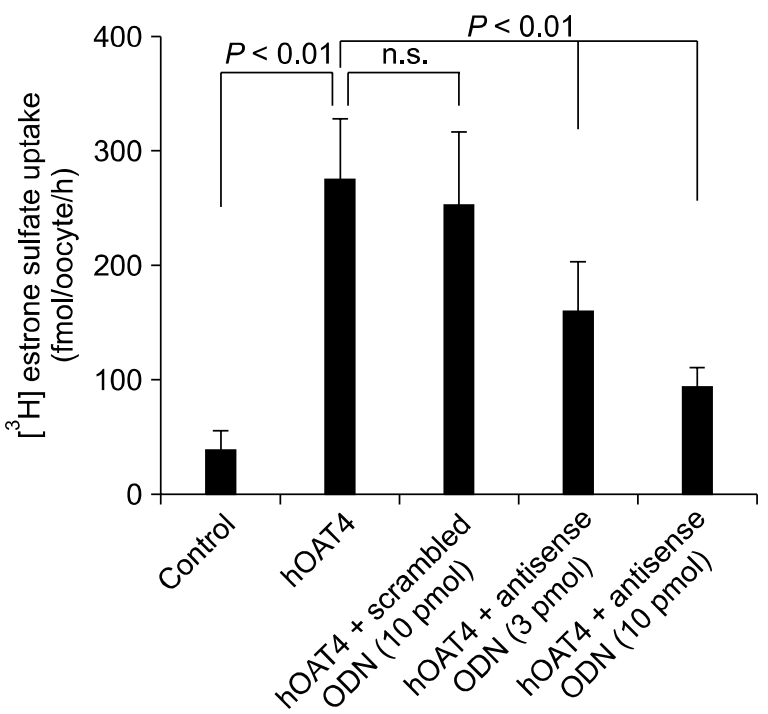

Figure 5. The effects of Xenopus laevis caveolin-1 scrambled or antisense oligodeoxynucleotide on hOAT4-mediated ${ }^{3} \mathrm{H}$ ] estrone sulfate uptake in Xenopus laevis oocyte expression system. (A) The expression of caveolin-1 in scrambled or antisense ODN injected oocytes. Membrane protein was extracted from 50 ODN injected oocytes and Western blot analysis was performed. (B) Defolliculated stage VI and V oocyte were injected with water, with hOAT4 cRNA (30 ng/oocyte), with hOAT4+scrambled ODN (3 pmol/oocyte), or with hOAT4 antisense ODN (10 pmol/oocyte). After 3 days, [ ${ }^{3} \mathrm{H}$ ] estrone sulfate $(100 \mathrm{nM})$ uptakes were determined for $1 \mathrm{~h}$. Each bar represents the mean \pm standard error for three experiments. Each experiment contains 8-10 oocytes. 
was not observed (Figure $3 \mathrm{D}$ and $\mathrm{E}$ ). When we examined 50 cells, above $80 \%$ of the tested cells showed a similar pattern.

\section{Western blot analysis using isolated caveolae-rich membrane fraction and immunoprecipitates by antibodies in the cultured trophoblasts}

In order to demonstrate the localization of hOAT4 to caveolae, we prepared caveolae-rich membrane fractions from trophoblasts and we analyzed the hOAT4 proteins in these fractions by Western blot analysis. As shown in Figure 4A, hOAT4 and caveolin-1 proteins were observed predominantly in the detergent-insoluble fractions numbered 3 and 4 or 3 , respectively. To determine whether there is a direct binding between the hOAT4 and caveolin-1, the lysates of trophoblasts were initially immuno-precipitated with the antibodies directed against hOAT4 or caveolin-1. The precipitates were subsequently electrophoresed by SDS-PAGE and the separated proteins were transferred to a membrane. The formation of a complex between the hOAT4 and caveolin-1 was analyzed by Western blot analysis using designated antibodies. The hOAT4 or caveolin-1 proteins did not precipitate with the control IgG (Figure 4B, designated as none). As shown in Figure 4B, the presence of the hOAT4 and caveolin-1 complex was detected upon precipitation with hOAT4 antibody (left panel). The presence of the hOAT4 and caveolin-1 complex could also be detected following precipitation with caveolin-1 antibody (right panel).

\section{Effect of caveolin-1 on uptake function of hOAT4}

In order to prepare the cDNA of hOAT4 containing the full sequence, we performed RT-PCR in cultured trophoblasts. We have successfully synthesized full-length hOAT4 and sub-cloned it to mammalian expression vector, pcDNA 3.1 (+) (sequencing data not shown). To determine the effect of caveolin-1 on $\left[{ }^{3} \mathrm{H}\right]$ estrone sulfate uptake by hOAT4 in a Xenopus oocyte expression system, Xenopus caveolin-1 scrambled and antisense ODN were employed. There was no change in the viability of oocytes among the groups injected with water, with hOAT4 cRNA, with hOAT4 cRNA + scrambled ODN or with hOAT4 cRNA + antisense ODN. The $\left[{ }^{3} \mathrm{H}\right]$ estrone sulfate $(100 \mathrm{nM})$ uptake in the hOAT4 cRNA injected oocytes showed a high uptake rate compared with that of the water injected oocytes. The amount of uptake in the hOAT4 cRNA injected oocytes and water injected oocytes was $39.4 \pm 15.8$ $\mathrm{fmol} /$ oocyte/h and $275.1 \pm 53.1 \mathrm{fmol} / \mathrm{oocyte} / \mathrm{h}$, respectively (Figure 5). When scrambled ODN was injected with hOAT4 CRNA, the uptake rate of $\left[{ }^{3} \mathrm{H}\right]$ estrone sulfate $(252.3 \pm 65.6 \mathrm{fmol} /$ oocyte/h$)$ was slightly decreased compared to that of the hOAT4 cRNA injected oocytes; however, this was without statistical significance. To demonstrate the effect of caveolin-1 on the function of hOAT4, we designed an antisense ODN in the open reading frame of Xenopus caveolin-1 (Xcaveolin-1). The uptake rates of $\left[{ }^{3} \mathrm{H}\right]$ estrone sulfate in the Xcaveolin-1 AODN (3 and 10 pmol/oocyte) with hOAT4 cRNA (30 ng/oocytes) co-injected oocytes was significantly decreased in a concentrationdependent manner (Figure 5) (3 pmol, $161.0 \pm$ $42.7 \mathrm{fmol} /$ oocyte $/ \mathrm{h} ; 10 \mathrm{pmol}, 95.6 \pm 15.0 \mathrm{fmol} /$ oocyte/h).

\section{Discussion}

Results obtained in the present study demonstrate for the first time that the hOAT4 in the cultured human placental trophoblasts is bound to caveolin-1 and the bound complexes are localized in the caveolae-enriched plasma membrane fraction. Several lines of evidences provided by this current study support this conclusion: 1) RT-PCR and immunoblot analysis indicated the expressional patterns of hOAT4 and caveolin-1 in the cultured human placental trophoblasts, 2) the overlaid confocal microscopic immuno-cytochemistry images of hOAT4 and caveolin-1 show that hOAT4 is colocalized with caveolin-1 in the plasma membrane, 3 ) the cross-over immuno-precipitation results show that the hOAT4 protein formed a bound complex with caveolin-1 protein, 4) using the Xenopus oocyte expression system, the functional analysis results of hOAT4 with or without Xenopus caveolin-1 antisense ODN reveal that the uptake function of hOAT4 is up-regulated by caveolin-1 under physiological conditions.

The hOAT4 is unique member among organic anion transporter family expressed in the placenta. Recently isolated hOAT4 is thought to play important role as a steroid sulfate conjugate transporter and also contributes elimination of clinically important drugs and endogenous organic anions (Khamdang et al., 2003; Ugele et al., 2003; Ekaratanawong et al., 2004). Even though the regulation mechanism of hOAT4 in the kidney has begun to be explored, its regulation mechanism in the placenta is largely unknown. Zhou and co-workers have shown that the function of hOAT4 was down regulated both by activation of PKC and by pregnancy-specific hormones progestetone in placental BeWo cells (Zhou et al., 2007). However, they have reported 
that progesterone-induced down regulated hOAT4 function is independent on PKC pathway. They also reported that hOAT4 activity was regulated by the protein-protein interaction with the multivalent PDZ (PSD-95, Drosophila discs-large protein, Zonula occludens protein 1) protein and $\mathrm{Na} / \mathrm{H}$ exchange regulatory factor-1 (NHERF1) in kidney derived cell line (Zhou et al., 2008). Miyazaki et al. also showed similar result using transfected human embryonic cells (Miyazaki et al., 2005). Interestingly, Zhou and co-workers showed that this regulatory mechanism by protein-protein interaction with PDZK1 and NHERF1 is occurred in kidney originated cell line but not in placenta originated BeWo cell line. Therefore, they suggest that regulatory partner protein in placenta is different from that in kidney. We have reported the function of OAT1 and OAT3 was regulated by proteinprotein interaction with the scaffolding protein, caveolin (Kwak et al., 2005a, 2005b). In the current study, we investigate the interaction of hOAT4 with caveolin-1 protein in primarily cultured human placental trophoblasts.

Caveolin is a compositional protein of caveolae which were flask-shaped vesicular invaginations in the plasma membrane, and they are rich in cholesterol, glycosphingolipids and sphingomyelin, and then are not solubilized by detergents. The membrane receptor molecules associated with signaling are known to be anchored to caveolae via caveolins and the caveolae have been implicated to function as the portals of signal transduction and in the vesicular transport processes (Lisanti et al., 1994; Couet et al., 1997). Several membrane associated signaling molecules are known to contain a common amino acid sequence motif (i.e., $\phi X \phi X X X X \phi, \phi X X X X \phi X X \phi$ or $\phi X \phi X X X X \phi X X \phi$ in which $\phi$ designates aromatic amino acids like Trp (W), Phe (F) or Tyr (Y) and X can be any amino acids) that recognizes the scaffolding domains that are present in caveolins. Considering the transmembrane topology of hOAT4, the primary amino acid sequence indicated the three potential caveolin-binding motifs (Figure 1). Among these, the second motif (FIWGLLSYRF) is candidate to bind with caveolin, which is located near the cytoplasmic face of the plasma membrane (amino acids 158-167).

In order to demonstrate the relationship between caveolin-1 and hOAT4, we performed functional uptake experiments using Xenopus caveolin-1 sense or antisense ODN in a Xenopus oocyte expression system. There have been two previous reports on the molecular features of Xenopus laevis caveolins. Razani and co-workers have reported the results of molecular cloning of $X$. laevis caveolins (Razani et al., 2002) and Sadler have reported the existence of caveolin-like protein in X. laevis oocytes (Sadler, 2001). The increase of $\left[{ }^{3} \mathrm{H}\right]$ estrone sulfate uptake by hOAT4 was significantly inhibited by the co-injection of antisense ODN, but not by scrambled ODN with hOAT4 cRNA. This result shows that caveolin-1 up-regulates the function of hOAT4 under the normal physiological condition. In speculation, a cause of functional regulation of hOAT4 by antisense oligodeoxynucleotide of caveolin-1 may be thought to be membrane trafficking of hOAT4 protein in placenta. Further molecular in vitro mutagenesis experimentation will be necessary to confirm the real binding site in hOAT4.

In conclusion, we report the protein-protein interaction of hOAT4 and caveolin-1. hOAT4 and caveolin-1 are co-localized in caveolae of the plasma membrane to form a protein-protein complex. The substrate uptake function of hOAT4 is upregulated by caveolin-1 under normal physiological conditions. Information from our present study might give some clues on the interacting partner of hOAT4 in placenta.

\section{Acknowledgement}

This work was supported by INHA University Research Grant.

\section{References}

Bischof P, Truong K, Campana A. Regulation of Trophoblastic Gelatinases by Proto-oncogenes. Placenta 2003;24:155-63

Cai C, Zhu H, Chen J. Overexpression of caveolin-1 increases plasma membrane fluidity and reduces P-glycoprotein function in Hs578T/Dox. Biochem Biophys Res Commun 2004;320:868-74

Cha SH, Sekine T, Fukushima JI, Kanai Y, Kobayashi Y, Goya $\mathrm{T}$, Endou $\mathrm{H}$. Identification and characterization of human organic anion transporter 3 expressing predominantly in the kidney. Mol Pharmacol 2001;59:1277-86

Cha SH, Sekine T, Kusuhara H, Yu E, Kim JY, Kim DK, Sugiyama $Y$, Kanai $Y$, Endou $H$. Molecular cloning and characterization of multispecific organic anion transporter 4 expressed in the placenta. J Biol Chem 2000;275:4507-12

Cha SH, Shin SY, Jung SY, Kim YT, Park YJ, Kwak JO, Kim $\mathrm{HW}$, Suh CK. Evidence for $\mathrm{Na}^{+} / \mathrm{Ca}^{2+}$ exchanger 1 association with caveolin-1 and -2 in C6 glioma cells. IUBMB Life 2004;56:621-7

Couet J, Li S, Okamoto T, Ikezu T, Lisanti MP. Identification of peptide and protein ligands for the caveolin-scaffolding domain. Implications for the interaction of caveolin with caveolae-associated proteins. J Biol Chem 1997;272:652533 
Ekaratanawong S, Anzai N, Jutabha P, Miyazaki H, Noshiro R, Takeda M, Kanai Y, Sophasan S, Endou H. Human organic anion transporter 4 is a renal apical organic anion/ dicarboxylate exchanger in the proximal tubules. J Pharmacol Sci 2004;94:297-304

Ganapathy V, Prasad PD, Ganapathy ME, Leibach FH. Placental transporters relevant to drug distribution across the maternal-fetal interface. J Pharmacol Exp Ther 2000; 294:413-20

Khamdang S, Takeda M, Babu E, Noshiro R, Onozato ML, Tojo A, Enomoto A, Huang XL, Narikawa S, Anzai N, Piyachaturawat $P$, Endou $\mathrm{H}$. Interaction of human and rat organic anion transporter 2 with various cephalosporin antibiotics. Eur J Pharmacol 2003;465:1-7

Knipp GT, Audus KL, Soares MJ. Nutrient transport across the placenta. Adv Drug Deliv Rev 1999;38:41-58

Kusuhara H, Sekine T, Utsunomiya-Tate N, Tsuda M, Kojima $\mathrm{R}$, Cha SH, Sugiyama Y, Kanai Y, Endou H. Molecular cloning and characterization of a new multispecific organic anion transporter from rat brain. J Biol Chem 1999;274:13675-80

Kwak JO, Kim HW, Oh KJ, Kim DS, Han KO, Cha SH. Co-localization and interaction of organic anion transporter 1 with caveolin-2 in rat kidney. Exp Mol Med 2005a;37:204-12

Kwak JO, Kim HW, Song JH, Kim MJ, Park HS, Hyun DK, Kim DS, Cha SH. Evidence for rat organic anion transporter 3 association with caveolin-1 in rat kidney. IUBMB Life 2005b;57:109-17

Kwak JO, Lee WK, Kim HW, Jung SM, Oh KJ, Jung SY, Huh $\mathrm{YH}$, Cha SH. Evidence for cyclooxygenase-2 association with caveolin-3 in primary cultured rat chondrocytes. J Korean Med Sci 2006;21:100-6

Lisanti MP, Scherer PE, Tang Z, Sargiacomo M. Caveolae, caveolin and caveolin-rich membrane domains: a signaling hypothesis. Trends Cell Biol 1994;4:231-5

McDonald KK, Zharikov S, Block ER, Kilberg MS. A caveolar complex between the cationic amino acid transporter 1 and endothelial nitric-oxide synthase may explain the "arginine paradox". J Biol Chem 1997;272: 31213-16

Meier PJ. Molecular mechanisms of hepatic bile salt transport from sinusoidal blood into bile. Am J Physiol 1995; 269:G801-12

Miyazaki H, Anzai N, Ekaratanawong S, Sakata T, Shin HJ, Jutabha P, Hirata T, He X, Nonoguchi H, Tomita K, Kanai Y, Endou $\mathrm{H}$. Modulation of renal apical organic anion transporter 4 function by two PDZ domain-containing proteins. J Am Soc Nephrol 2005;16:3498-506

Monte JC, Nagle MA, Eraly SA, Nigam SK. Identification of a novel murine organic anion transporter family member, OAT6, expressed in olfactory mucosa. Biochem Biophys Res Commun 2004;323:429-36

Muller M, Jansen PL. Molecular aspects of hepatobiliary transport. Am J Physiol 1997;272:G1285-303

Pascolo L, Fernetti C, Pirulli D, Crovella S, Amoroso A, Tiribelli C. Effects of maturation on RNA transcription and protein expression of four MRP genes in human placenta and in BeWo cells. Biochem Biophys Res Commun 2003;303: 259-65

Pritchard JB, Miller DS. Mechanisms mediating renal secretion of organic anions and cations. Physiol Rev 1993;73:765-96

Razani B, Park DS, Miyanaga Y, Ghatpande A, Cohen J, Wang XB, Scherer PE, Evans T, Lisanti MP. Molecular cloning and developmental expression of the caveolin gene family in the amphibian Xenopus laevis. Biochemistry 2002;41:7914-24

Sadler SE. Low-density caveolae-like membrane from Xenopus laevis oocytes is enriched in Ras. J Cell Biochem 2001;83:21-32

Sekine T, Watanabe N, Hosoyamada M, Kanai Y, Endou H. Expression cloning and characterization of a novel multispecific organic anion transporter. J Biol Chem 1997; 272:18526-9

Sekine T, Cha SH, Endou H. The multispecific organic anion transporter (OAT) family. Pflugers Arch 2000;440:337-50

Stulc J. Placental transfer of inorganic ions and water. Physiol Rev 1997;77:805-36

Sun W, Wu RR, van Poelje PD, Erion MD. Isolation of a family of organic anion transporters from human liver and kidney. Biochem Biophys Res Commun 2001;283:417-22

Sweet DH, Wolff NA, Pritchard JB. Expression cloning and characterization of ROAT1: The basolateral organic anion transporter in rat kidney. J Biol Chem 1997;272:30088-95

Ugele B, St-Pierre MV, Pihusch M, Bahn A, Hantschmann P. Characterization and identification of steroid sulfate transporters of human placenta. Am J Physiol Endocrinol Metab 2003;284:E390-8

Ullrich KJ, Rumrich G. Renal transport mechanisms for xenobiotics: chemicals and drugs. Clin Investig 1993;71: 843-8

Youngblood GL, Sweet DH. Identification and functional assessment of the novel murine organic anion transporter Oat5 (Slc22a19) expressed in kidney. Am J Physiol 2004;287:F236-44

Zhou F, Hong M, You G. Regulation of human organic anion transporter 4 (hOAT4) by progesterone and protein kinase $\mathrm{C}$ in human placental BeWo cells. Am J Physiol Endocrinol Metab 2007;293:E57-61

Zhou F, Xu W, Tanaka K, You G. Comparison of the interaction of human organic anion transporter hOAT4 with PDZ proteins between kidney cells and placental cells. Pharm Res 2008;25:475-80 